\title{
SHS AND RHS STAINLESS STEEL BEAM-COLUMNS BEHAVIOUR
}

\author{
B. Židlický", M. Jandera**
}

\begin{abstract}
Behaviour of stainless steel square hollow section and rectangular hollow section (SHS and RHS) members loaded by compression and major axis bending is investigated in this research. All of the three main stainless steel groups are considered, namely austenitic, ferritic and duplex. Comprehensive numerical parametric study was conducted by using finite element software Abaqus. Numerical model was validated based on the experimental data. Together 20 experiments were conducted consists of both SHS and RHS specimens. Results of the numerical parametric study provided sufficient amount of data on the basis of which the new interaction factor formulae were developed. The new formulae have no dependency on the material properties and cross-section slenderness and the evaluation of the stainless steel beam-columns design considering the new interaction factor calculation is presented herein.
\end{abstract}

Keywords: Stainless steel, Beam-column, Interaction factor, Member slenderness.

\section{Introduction}

This paper is focused on the stainless steel SHS and RHS members loaded by combination of axial compressive force and major axis bending. Only the uniform bending moment distribution along the member length is considered. There is a codified design approach given by stainless steel code EN 19931-4 (2006) which is with other procedures developed by researchers evaluated in Jandera et al. (2017) and Židlický and Jandera (2017). All procedures exhibit some deviations, in general. Recently presented research of the stainless steel beam-columns design Židlický and Jandera (2018) provides a new interaction factor formulae. However, it was limited only to the SHS members.

The extension of the Židlický and Jandera (2018) procedure by the RHS members is shown in this paper and slight improvement of the interaction factor formulae is proposed and evaluated.

\section{Experimental program}

Together 20 experiments was conducted, namely 12 SHS members and 8 RHS members were tested. Material properties were obtained from the tensile tests. Four coupons were extracted from each crosssection -2 coupons from the flat part of the cross-section and 2 from the corner part of the cross-section where are different material properties due to cold-working.

\section{Numerical model}

To numerical modelling was used the FE (finite element) software Abaqus. A 3D model using S4R element (four-node shell element with reduced integration) was created. Geometrically and materially non-linear analysis with imperfections (GMNIA method) was used for calculations. Boundary conditions and loading were implemented to the reference points situated at the member centroid at members both ends. The

Ing. Břetislav Židlický: Faculty of Civil Engineering, Czech Technical University in Prague; Thákurova 7; 166 29, Prague; CZ, bretislav.zidlicky@fsv.cvut.cz

doc. Ing. Michal Jandera, Ph.D.: Faculty of Civil Engineering, Czech Technical University in Prague; Thákurova 7; 16629 , Prague; CZ, michal.jandera@fsv.cvut.cz 
reference points were rigidly coupled with the member edges. Both global and local imperfections were considered with amplitudes $L / 1000$ (where $L$ is the member length) and calculated according to Dawson and Walker (1972) formula, respectively. Both imperfections were introduced through the appropriate eigen-modes.

Validation of the numerical model for SHS members have been made and was described in Židlický and Jandera (2017) in detail.

\section{Numerical parametric study}

Recent numerical study conducted by Židlický and Jandera (2018) containing only SHS members was extended by RHS members. Cross-section of $40 \times 100 \mathrm{~mm}$ dimensions and thickness of the wall from 2 to $6 \mathrm{~mm}$ were considered in order to cover cross-section Classes 1, 3 and 4. The investigated member slenderness (Table 1) led to the calculation of the member lengths. Both austenitic, ferritic and duplex stainless steel groups provided by EN 1993-1-4 (2006) were considered in the numerical study. All of these grades were considered twice regarding the different strain hardening factor $n$. Due to appropriate material selection the materials with low yield strength $f_{\mathrm{y}}$ and ultimate strength $f_{\mathrm{u}}$ (ferritic), low $f_{\mathrm{y}}$ and $\operatorname{high} f_{\mathrm{u}}$ (duplex) and the greatest ratio of $f_{\mathrm{u}}$ to $f_{\mathrm{y}}$ (austenitic) are covered. The Young modulus of elasticity $E_{0}$ is considered according to EN 1993-1-4 (2006) for all considered materials. Material properties are summarized in Table 2.

Tab. 1: Member slenderness values.

\begin{tabular}{llllll}
\hline $\bar{\lambda}$ & 0.5 & 0.8 & 1.0 & 1.5 & 2.0 \\
\hline
\end{tabular}

Tab. 2: Material properties.

\begin{tabular}{ccccc}
\hline Grade & $\boldsymbol{E}_{\mathbf{0}}[\mathbf{M P a}]$ & $\boldsymbol{f}_{\mathbf{y}}[\mathbf{M P a}]$ & $\boldsymbol{f}_{\mathbf{u}}[\mathbf{M P a}]$ & $\boldsymbol{n}$ \\
\hline Ferritic & 200000 & 210 & 380 & 4.5 \\
\hline Ferritic & 200000 & 210 & 380 & 14 \\
\hline Duplex & 200000 & 480 & 660 & 4.5 \\
\hline Duplex & 200000 & 480 & 660 & 14 \\
\hline Austenitic & 200000 & 220 & 520 & 4.5 \\
\hline Austenitic & 200000 & 220 & 520 & 14 \\
\hline
\end{tabular}

Both axial compressive force and uniform bending moment were introduced through the reference points at the member centroid. Their values were preliminary predicted according to Zhao (2015) procedure. Various values of the compressive force $N_{\mathrm{Ed}}$ to $N_{\mathrm{b}, \mathrm{Rd}}$ ratios, expressed as $n_{\mathrm{b}}$, were considered, see Table 3. Flexural buckling resistance $N_{\mathrm{b}, \mathrm{Rd}}$ and bending resistance $M_{\mathrm{b}, \mathrm{Rd}}$ were obtained from numerical calculation.

Tab. 3: Investigated $n_{\mathrm{b}}$ values.

\begin{tabular}{llllll}
\hline$n_{\mathrm{b}}$ & 0.05 & 0.1 & 0.2 & 0.5 & 0.8 \\
\hline
\end{tabular}

\section{New proposal}

A new procedure for stainless steel SHS beam-columns design was developed by Židlický and Jandera (2018). Based on the new data obtained from the numerical parametric study it was evaluated for RHS members and slight improvement was suggested. The same interaction formula as provided by the code EN 1993-1-4 (2006) was considered, see Equation (1), only the interaction factor formulae were modified, see Equations (2) and (3). Evaluation of both SHS and RHS members is shown in Figures 1 and 2 providing results of the interaction formulae with dependency on member slenderness $\bar{\lambda}_{\mathrm{y}}$ and $n_{\mathrm{b}}$ ratio, respectively. Values greater than unity indicate safe results. Table 4 provides average value and standard deviation of the results and complex statistical evaluation according to Afshan et al. (2015). 


$$
\begin{gathered}
\frac{N_{\mathrm{Ed}}}{N_{b, R d}}+k_{y} \frac{M_{\mathrm{Ed}}}{M_{\mathrm{b}, \mathrm{Rd}}} \leq 1 \\
k_{y}=1+1.5 \bar{\lambda}_{\mathrm{y}} n_{\mathrm{b}}^{\beta} \text { for } \quad \bar{\lambda}_{\mathrm{y}} \leq 1.0 \\
k_{y}=1+1.5 \bar{\lambda}_{\mathrm{y}} n_{\mathrm{b}}^{\beta} \frac{0.8}{\sqrt{\bar{\lambda}_{\mathrm{y}}-0.36}} \text { for } \quad \bar{\lambda}_{\mathrm{y}}>1.0
\end{gathered}
$$

where $N_{\mathrm{Ed}}$ is the design compressive force,

$M_{\mathrm{Ed}}$ is the design bending moment,

$N_{\mathrm{b}, \mathrm{Rd}}$ is the flexural buckling resistance,

$M_{\mathrm{b}, \mathrm{Rd}}$ is the bending resistance,

$k_{\mathrm{y}} \quad$ is the interaction factor,

$\bar{\lambda}_{\mathrm{y}} \quad$ is the member slenderness,

$n_{\mathrm{b}} \quad$ is the $N_{\mathrm{Ed}}$ to $N_{\mathrm{b}, \mathrm{Rd}}$ ratio,

$\beta \quad$ is calculated as $\left(M_{\mathrm{el}} / M_{\mathrm{b}, \mathrm{Rd}}\right)^{2}$.

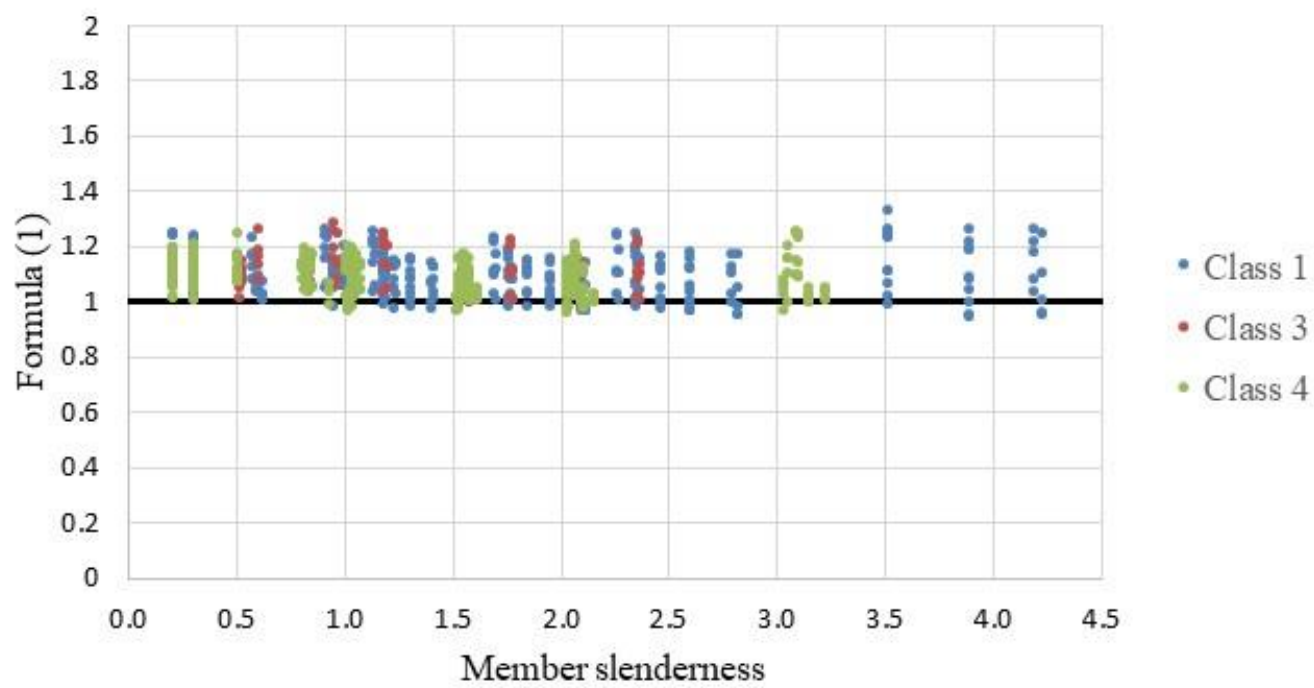

Fig. 1: Evaluation of the modified proposal $-\bar{\lambda}$.

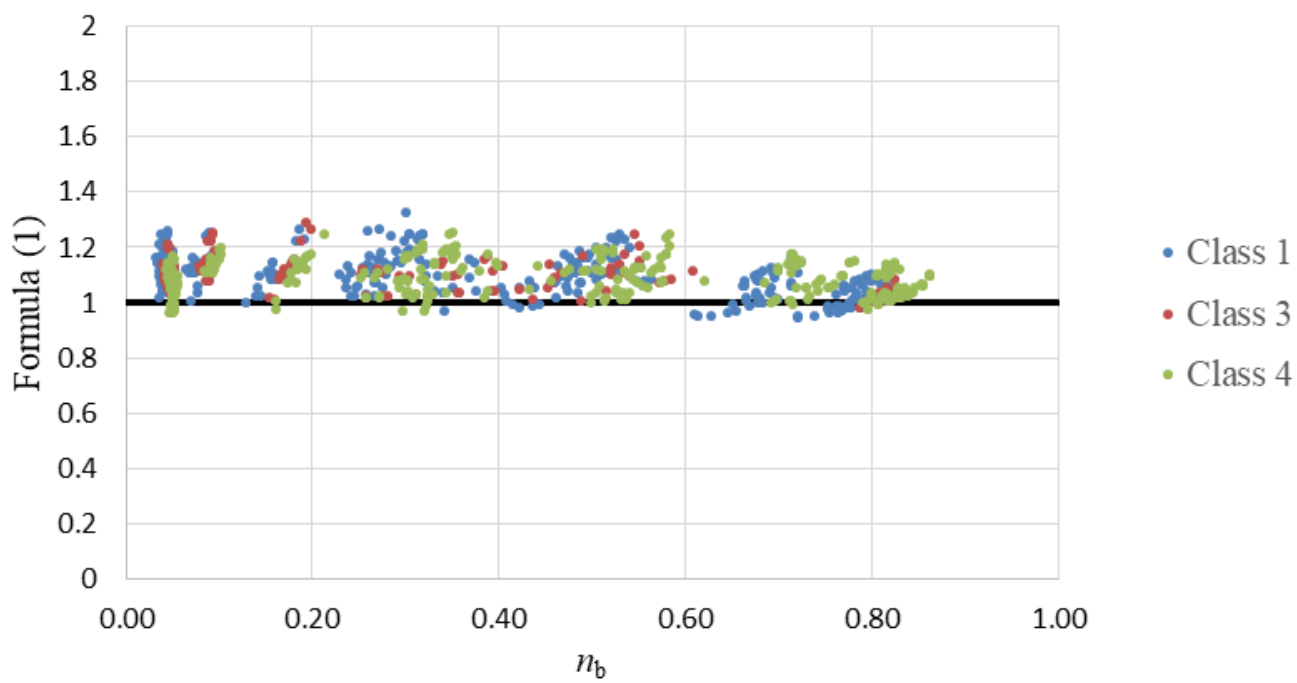

Fig. 2: Evaluation of the modified proposal $-n_{b}$. 
Tab. 4: Statistical evaluation.

\begin{tabular}{cc}
\hline Average value & 1.096 \\
\hline Standard deviation & 0.069 \\
\hline$\gamma_{M}$ & 1.087
\end{tabular}

As could be seen in Figures 1 and 2, the new proposal provides safe and consistent results for both SHS and RHS stainless steel beam-columns. There is no dependency on member slenderness, cross-section slenderness (Class of the cross-section), material behaviour and $n_{\mathrm{b}}$ ratio. The statistical evaluation shows low standard deviation and slightly conservative average value. This is due to requirement of the complex statistical evaluation according to Afshan et al. (2015) where $\gamma_{M}$ should be lower than partial safety factor $\gamma_{\mathrm{M} 1}$ for stainless steel given by EN 1993-1-4 (2006) which is equal to 1.1 value. In sum, statistical evaluation confirmed safety of the proposal. That makes the proposed procedure very general, safe and effective for the stainless steel SHS and RHS beam-columns design.

\section{Conclusions}

Presented paper deals with stainless steel SHS and RHS beam-column behaviour. Despite the fact that many design approaches exists, none of them is safe and accurate enough for all investigated parameters. A new procedure was developed by Židlický and Jandera (2018), however it is limited only for SHS members. Evaluation of this procedure for both SHS and RHS members was made and slight improvement was suggested.

Comprehensive numerical parametric study of RHS members was made in software Abaqus. 3D shell element model using GMNIA method was created and successfully validated based on the experimental data.

Evaluation of the proposed procedure for both SHS and RHS stainless steel beam-columns was presented in this paper. The improved approach indicates safe and accurate results for all investigated variable parameters. Therefore, the proposed procedure is suitable for the stainless steel SHS and RHS beamcolumns.

Further investigation of the suitability of the proposed approach for the stainless steel open section beamcolumns will follows.

\section{Acknowledgement}

The support of the Czech Science Foundation grant 17-247695 "Nonlinear stability and strength of slender structures with nonlinear material properties" is gratefully acknowledged.

\section{References}

Afshan, S., Francis, O., Baddoo, N. and Gardner, L. (2015) Reliability analysis of structural stainless steel design provision. Journal of Constructional Steel Research, 114, pp. 293-304.

Dawson, R.G. and Walker, A.C. (1972) Post-buckling of geometrically imperfect plates. Journal of the Structural Division ASCE, 98, pp. 75-94.

EN 1993-1-4 (2006) Eurocode 3: Design of steel structures - Part 1-4: General rules - Supplementary tules for stainless steel. CEN, Brussels.

Jandera, M., Syamsuddin, D. and Židlický, B. (2017) Stainless steel beam-column behaviour. Open Civil Engineering Journal, 11, pp. 358-368.

Zhao, O. (2015) Structural Behaviour of Stainless Steel Elements Subjected to Combined Loading. Ph.D. Thesis. Imperial College London, Great Britain.

Židlický, B. and Jandera, M. (2017) Combined loading of slender stainless steel SHS/RHS members. Eurosteel 2017, Copenhagen, Denmark.

Židlický, B. and Jandera, M. (2018) SHS and RHS stainless steel slender beam-columns. Engineering Mechanics 2018, Svratka, Czech Republic. 